Dicle Tıp Dergisi / Dicle Med J (2019) 46 (3) : 419 - 427

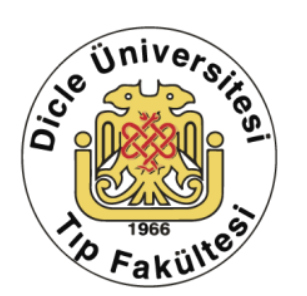

WWW.diclemedj.org

Özgün Araștırma / Original Article

\title{
Lomber Disk Hernisine Bağlı Radikülopatili Hastalarda Floroskopi Eşlikli LomberTransforaminalEpidural Enjeksiyonun Etkinliği
}

\author{
Mehmet Sabri Gürbüz ${ }^{1}$ \\ 1 İstanbul Medeniyet Üniversitesi Tıp Fakültesi, Nöroşirürji Anabilim Dall, İstanbul, Türkiye ORCID: 0000-0002-3764-389X
}

Geliş: 21.02.2019; Revizyon: 17.05.2019; Kabul Tarihi: 25.06.2019

Öz

Amaç: Lomber disk hernisine bağlı radikülopatili hastalarda lomber transforaminal epidural enjeksiyonun (TFEE) etkinliğinin araştırılması.

Yöntemler: TFEE yapılan ve çalışma kriterlerini karşılayan 80 hasta retrospektif olarak incelendi. Tüm hastalara aynı yöntem ile C-kollu floroskopi eşliğinde, radikülopatinin olduğu taraf ve seviyeye, radyoopak madde ile hedeflenen foramen teyit edildikten sonra $40 \mathrm{mg}$ metilprednisolon asetat ve $20 \mathrm{mg}$ bupivacaine karışımı enjekte edildi. İşlem öncesi görsel analog skala (VAS) değerleri, işlem sonrası 3. saat, işlem sonrası 1. ay ve işlem sonrası 3. ay VAS

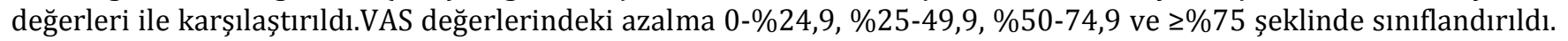
Üçüncü ayın sonundaki VAS değerlerinde işlem öncesine göre en az \% 50 azalma olan olgularda işlem başarılı kabul edildi. Ayrıca işlem başarısı ile yaş, cinsiyet, vücut kitle indeksi (VKI) ve semptom süresi arasındaki ilişki değerlendirildi.

Bulgular: Toplam 80 olgu arasından, 65 olguda $(\% 81,3)$ işlem başarılı olurken, 15 olguda $(\% 18,7)$ ise işlem başarısız olmuştur. Semptom süresi 6 aydan kısa olan olgularda başarı oranı \% 80 iken, semptom süresi 6 ay ve daha uzun olan olguların başarı \% 20 olarak saptanmıştır $(\mathrm{p}<0,01)$. Yaş, cinsiyet, seviye, taraf, VKİ ile işlem başarısı arasında anlamlı bir ilişki saptanmamıştır. VAS değerindeki azalma işlem sonrası 3. saatte ortalama \%84; 1.ayda \%71,9, 3.ayda ise $\% 65,5$ olarak saptanmıştır.

Sonuçlar: Lomber disk hernisine bağlı radikülopatili hastalarda hasta seçimi iyi yapıldığında, TFEE ağrı kontrolü açısından orta vadede etkin bir yöntemdir. Semptom süresi 6 aydan uzun olan olgularda ise bu etkinlik azalmaktadır.

Anahtar kelimeler: Lomber disk hernisi, radikülopati, transforaminal epidural enjeksiyon, etkinlik, başarı oranı.

DOI: 10.5798/dicletip.620333

Yazışma Adresi / Correspondence: Mehmet Sabri Gürbüz, Eğitim Mah. Dr. Erkin Cad. 34722 Kadıköy/İstanbul,Türkiye e-mail: mehmetsabrigurbuz@gmail.com 


\title{
The effectiveness of Fluoroscopy-guided Transformational Epidural Injection in Radiculopathy Secondary to Lumbar Disc Herniations
}

\begin{abstract}
Objective: To analyze the effectiveness of transforaminal epidural injection (TFEI) in patients with radiculopathy secondary to lumbar disc herniations.

Method: Eighty patients undergoing TFEI and meeting study criteria were analyzed retrospectively. A mixture of 40 mg of methylprednisolone acetate and $20 \mathrm{mg}$ of bupivacaine was injected to the site and the level of the radiculopathy after confirmation of the targeted foramen with radiopaque agent under C-armed fleuroscopic guidance. Pre-injection visual analogue scale (VAS) values were compared to the post-injection, 1-month post-injection and 3-month postinjection VAS values. Reduction in VAS values were grouped as $0-\% 24.9,25-49.9 \%, 50-74.9 \%,>75 \%$. The procedure was considered successful when at least $50 \%$ of VAS reduction is achieved at the end of the 3rd month of the procedure compared to the pre-injection VAS value. Association between age, sex, body mass index (BMI), symptom duration and success of the procedure was also evaluated.

Results: Of the total of 80 patients, success was achieved in 65 patients (81.3\%) whereas 15 patients (18.7\%) failed. Success rate was $80 \%$ in patients with symptom duration of $<6$ months and $20 \%$ in patients with symptom duration of $>6$ months. No significant association was found between age, sex, level, side, BMI and success rate of the procedure. The general reduction of VAS was $84 \%$ at the third hour of injection, $71.9 \%$ at the 1st month of injection and $65.5 \%$ at the $3 \mathrm{rd}$ month of injection.

Conclusions: TFEI is an effective procedure for mid-term pain control in the patients with radiculopathy secondary to lumbar disc herniations when a careful patient selection is provided. Effectiveness of the procedure relatively decreases in the patients with a symptom duration of more than 6 months.
\end{abstract}

Keywords: Lumbar disc herniation, radiculopathy, transforaminal epidural injection, effectiveness, success rate.

\section{GíRIS}

Bel ağrısı toplumda oldukça sık görülen bir hastalık olup çoğu mekanik bel ağrısı şeklindedir. Bel ağrısı yakınması olan hastaların yaklaşık \%3 ile 4'ünde ise lomber dar kanal veya lomber disk hernisi saptanmaktadır ${ }^{1}$. Ciddi lomber disk hernisi olan hastalarda spinal kök basısına bağlı bacak boyunca yayılan ağrı yaygın olarak görülmektedir. Bu hastaların yaklaşık \%80'inin yakınmaları istirahat, ilaç tedavisi ve fizik tedavi yöntemleriyle geçmektedir. Konservatif tedaviye yanıt vermeyen, radikülopatiye neden olan, hastanın hayat kalitesini bozan, ilerleyici nörolojik defisit, idrar veya gaytainkontinansı gibi ciddi nörolojik bulgularla başvuran hastalara cerrahi diskektomi yapılmaktadır ${ }^{2,3}$. Bununla birlikte mutlak cerrahi endikasyonu olmayan ancak radikülopati yakınmaları olup konservatif tedavilere yanıt vermeyen disk hernilerinde ağrı kontrolüne yönelik yapılan transforaminalepiduralenjeksiyon

(TFEE) oldukça başarılı sonuçlar vermektedir ${ }^{3-5}$. Bu çalışmada lomber disk hernisine bağlı radikülopatisi olan ve konservatif tedaviye yanit vermeyen hastalarda transforaminal epidural enjeksiyonunun başarı oranları incelendi.

\section{YÖNTEMLER}

\section{Hastalar}

Çalışma üç farklı kurumda 2014-2017 yılları arasında bel ve tek taraflı bacak ağrısı yakınmalarıyla başvuran lomber disk hernili 80 hastaya tek nöroşirürjiyen tarafından yapılan toplam 80 transforaminal epidural enjeksiyon işlemlerini kapsamaktadır. Hastalar ve yapılan işlem ile bilgiler kurum ve kişisel arşiv kayıtları incelenerek değerlendirilmiştir. İlgili kurumlardan etik kurul onayı alınmıștır.

Çalışmaya en az 4 haftalık, konservatif yöntemlerle geçmeyen bel ve bacak ağrısı yakınmaları öyküsü olan, işlem öncesi düz 
bacak germe testi (DBG) testi müspet olan, radikülopati tespit edilen tek taraflı disk hernisi olan hastalar dâhil edilmiştir. Çalışmaya dâhil edilen tüm hastaların tanıları lomber MR tetkikleri yapılarak konmuştur. Tüm hastaların işlem öncesi hemogram, rutin biyokimya ve pıhtılaşma testleri değerlendirilmiş olup, aydınlatılmış onam alındıktan sonra işlem gerçekleştirilmiştir.

Enjeksiyon yapılacak seviyede cerrahi geçirmiş olan, nörolojik defisiti olan, bacak ağrısı ön planda olmayan veya çok hafif olan, cerrahi endikasyonu olan, lomber MR tetkikinde ekstrüde, sekestre veya serbest disk fragmanı olan, çoklu seviye enjeksiyon yapılan, disk hernisinden ziyade ileri derece faset ve ligamentum flavum hipertrofisine bağlı lateral resesstenozu olan hastalar çalışma dışı birakıldı.

\section{İşlem Tekniği}

Hastalara damar yolu açlldıtan sonra ameliyathaneye alındı. Hastalar floroskopik görüntülemeye uygun olan ameliyat masasına alınarak pron pozisyon verildi. Karın altı bir yastıkla desteklendi ve masaya hafif fleksiyon verildi. Hastaya mümkün olduğu kadar iyatrojenik kök iritasyonunu baskılamaması için sedoanaljezi verilmedi. İşlem yapılacak seviye C-kollu floroskopiyle tespit edildi. Orta hat belirlenip spinözprosesler tam orta hatta olacak şekilde görüntü alındı. Ardından orta hattın $10 \mathrm{~cm}$ laterali işaretlendi. İşlem yapılacak alan iyodin bazlı solüsyon ile geniș olarak silindikten sonra steril olarak örtüldü. Önce son plakların birbirine paralel ve düz çizgi olması sağlandı. Daha sonra anteroposterior (AP) skopi eşliğinde $21 \mathrm{G}$ spinal iğne ile daha önce belirlenen noktadan girildi ve faset hissedildi. Daha sonra iğne sagital planda 45 derece açlanacak şekilde fasetin altına yerleștirildi (Şekil 1). Bu arada hasta bacak boyunca ağrı hissederse ona göre iğne gerekli manipülasyonlarla foramene yerleştirildi.
Ardından lateralskopi görüntüsü alınarak iğne ucu foremende olacak șekilde yerleștirildi.

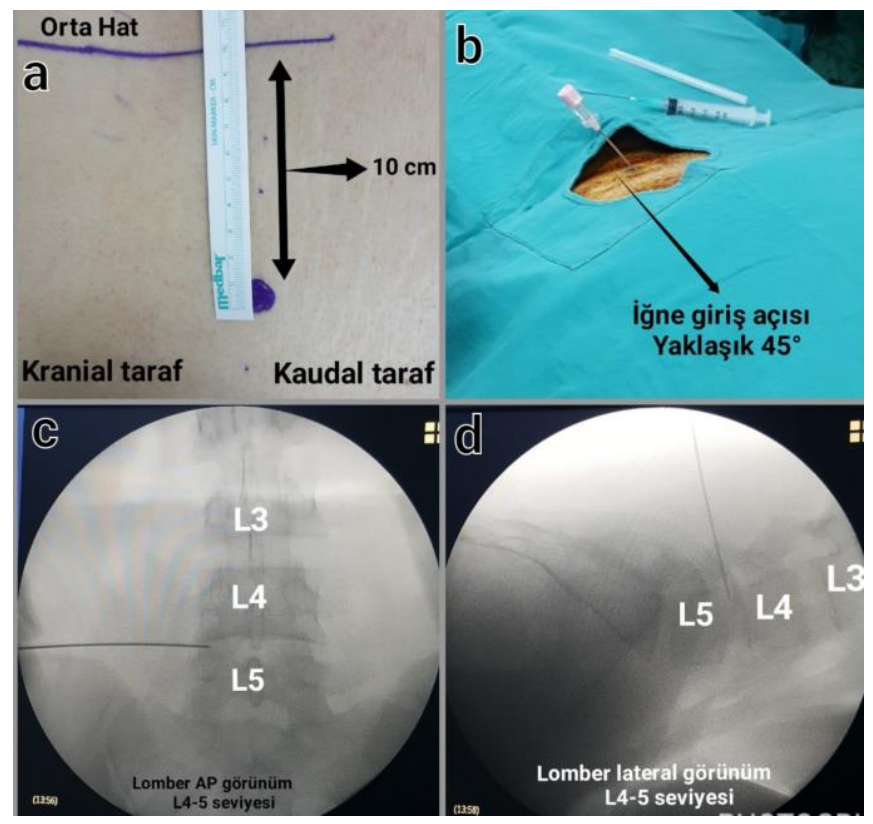

Şekil 1: Transforaminal epidural enjeksiyon yapılan hastada iğne giriş yerinin ölçülerek belirlenmesi (a), iğnenin sagital düzlemde giriş açısı (b) görülmektedir. İğnenin anteroposterior (c) ve lateral (d) floroskopi eşliğinde L4-5 seviyesinde foramene yerleștirilmesi görülmektedir.

Aspirasyon yapılarak iğne ucunun vasküler yapılara girmediğinden emin olundu. $1 \mathrm{ml}$ opak madde verilerek opak maddenin kök boyunca foramende yayıldığı gözlendi. Son olarak $1 \mathrm{ml}$ (40 mg) metilprednizolon asetat ve $4 \mathrm{ml}$ bupivacain ehidroklorür $\% 0,5$ solüsyonu karışımı enjekte edildi ve iğne çekilerek işlem sonlandırıldı (Şekil 2). L5-S1 seviyesi dışındaki seviyelerde standart olarak bu teknik kullanıldı. Ancak L5-S1 seviyesinde ise iğne giriş yeri floroskopi klavuzluğunda iliak kanat poziyonuna göre orta hata daha yakın ve giriş açısı sagital düzlemde daha az açıyla (daha dik) olacak şekilde yapıldı. Hastalar işlem sonrasında en az 3 saat klinikte yatarak takip edildikten ve sorunsuz mobilize edildikten sonra taburcu edildi. 


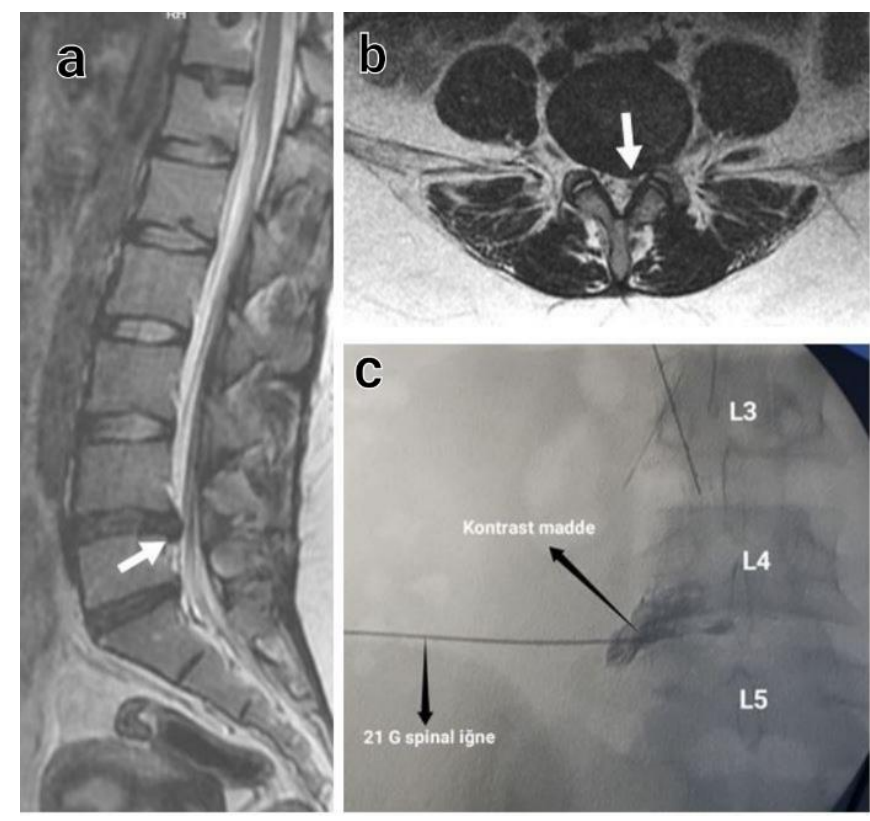

Şekil 2: Lomber T-2 ağırlıklı sagital manyetik rezonans görüntüleme (MRG) kesitinde (a) ve lomber T-2 ağırlıklı sagital MRG kesitinde (b) sol L 5 foramenini daraltan ve sol L5 sinir köküne basıya neden olan protrüde disk hernisi beyaz oklarla gösterilmektedir. Lomber anteroposterior floroskopi görüntüsünde verilen opak maddenin foramende kök boyunca yayılımı görülmektedir (c).

\section{Değerlendirme parametreleri}

Yazarın TFEE yaptığı tüm hastalara, 3. saatte, 1 . ayda ve 3. ayda, çalışmaya dâhil edilsin ya da edilmesin, rutin kontrol yapılmaktadır. Tüm hastalar belirtilen aralıklarda kontrole çağrılmakta, kayıtları tutulmakta ve hastalar her kontrolde bir sonraki kontrol için bilgilendirilmektedir.

Hasta dosyalarından veya yetersiz ise telefonla ulaşılarak hastaların demografik bilgileri, semptom süreleri, hastaların işlem öncesi, işlem sonrası üçüncü saat, işlem sonrası birinci ay ve işlem sonrası üçüncü ay bacak ağrısı görsel analog skala (VAS) değerleri kaydedildi. İşlem sonrasında her bir VAS değerinin işlem öncesine göre yüzde kaç azaldığı kaydedildi. VAS değerlerindeki azalma <\%25, \%25-49,9, $\% 50-75,>\% 75$ şeklinde sinıflandırıldı. Literatürde önerildiği gibi üçüncü ay sonunda işlem öncesine göre VAS değerinde $\% 50$ azalma olan olgularda işlem başarılı kabul edildi6,7.
İşlemin başarı oranı ve başarıyı etkileyen faktörler (yaş, cinsiyet, vücut kitle indeksi, semptom süresi) ile varsa ilişkisi araştırıldı. İşlem öncesi semptom süreleri literatürde önerildiği üzere 6 aydan kısa ve 6 aydan uzun olmak üzere kategorize edildi ${ }^{6-8}$.

\section{Ístatistiksel Analiz}

İstatistiksel analizler için NCSS (NumberCruncher Statistical System) 2007 Statistical Software (Utah, USA) programı kullanıldı. Çalıșma verileri değerlendirilirken tanımlayıcı istatistiksel metodların (Ortalama, Standart sapma, medyan, sıklık, oran) yanı sıra verilerin normal dağılıma uygunluklarında ShaproWilks test ve boxPlot grafikler kullanılmıştır. Normal dağılım gösteren değișenlerin iki gruba göre değerlendirmelerinde Student $t$ test kullanılırken; normal dağılım göstermeyen değişkenlerin değerlendirilmesinde Mann Whitney U test kullanıldı. Niteliksel verilerin karşılaştırılmasında ise Ki-Kare testi, Fisher's Exact test ve Fisher -Freeman Halton test kullanıldı. Sonuçlar \% 95'lik güven aralığında, anlamlılık $\mathrm{p}<0.05$ düzeyinde değerlendirildi.

\section{BULGULAR}

Çalışma 2014-2017 yılları arasında yapılan toplam 96 TFEE işlemleri arasından çalışma kriterlerini karşılayan \%46,3'ü (n=37) kadın, $\% 53,8$ 'i $(n=43)$ erkek olmak üzere toplam 80 olgu ile yapılmıştır. Olguların yaşları 16 ile 66 arasında değişmekte olup, ortalama 36.69 \pm 9.50 yildır.

Olguların vücut kitle indeksi (VKI) ölçümleri 17 ile 39 arasında değişmekte olup ortalaması $25.55 \pm 4.82$ olarak bulundu. Olguların \%68,8'inde (55) semptom süresi 6 ayın altında iken $\% 31,2$ 'inde ise 6 ay ve üzerindedir. Olguların \%46,3'ünde (37) işlem sağ tarafta, $\% 53,8$ 'inde (43) ise sol tarafta uygulanmıştır. Seviyeler incelendiğinde \%2,5'inde L1-L2; $\% 6,3$ 'ünde L2-L3, \%18,8'inde L3-L4; $\% 53,7$ 'sinde L4-L5 ve $\% 18,7$ 'sinde L5-S1'dir. 
Toplam $65 \quad(\% 81,3)$ olguda işlem başarılı olurken, 15 olguda $(\% 18,7)$ ise işlem başarısız olmuştur. Başarısız olan olgulardan 1 tanesinde 3. ayın sonunda cerrahi diskektomi gereksinimi olmuştur. Başarı durumuna göre olguların yaş, cinsiyet, VKİ, işlemin yapıldığı seviye ve tarafa göre dağılımları arasında anlamlı farklılık saptanmamıştır ( $p>0,05)$. Semptom süresi 6 aydan kısa olan olgularda başarı oranı \%80 iken, semptom süresi 6 ay ve daha uzun olan olguların başarı \%20 olarak saptanmıștır $(\mathrm{p}<0,01)$ (Tablo 1).

Tablo 1: Hastaların demografik özellikleri, seviye, taraf ve semptom süresi ve bu değişkenlerin işlem başarısı ile ilișkisi.

\begin{tabular}{|c|c|c|c|c|}
\hline \multicolumn{2}{|c|}{$\begin{array}{c}\text { Demografik } \\
\text { özellikler } \\
\end{array}$} & \multirow{2}{*}{\begin{tabular}{|c|} 
Başarılı \\
$16-66(39)$
\end{tabular}} & \multirow{2}{*}{\begin{tabular}{|l|} 
Başarısız \\
$29-52(37)$
\end{tabular}} & \multirow{2}{*}{$\frac{p}{{ }^{a} 0.804}$} \\
\hline \multirow{2}{*}{ Yaş (yıl) } & $\begin{array}{l}\text { Min-Mak } \\
\text { (Medyan) }\end{array}$ & & & \\
\hline & Ort $\pm S s$ & $38.81 \pm 10.04$ & $38.13 \pm 6.98$ & \\
\hline \multirow{2}{*}{$\begin{array}{c}\text { Vücut } \\
\text { kitle } \\
\text { indeksi }\end{array}$} & $\begin{array}{l}\text { Min-Mak } \\
\text { (Medyan) }\end{array}$ & $17-39(25)$ & $18-36(24)$ & ${ }^{a} 0.564$ \\
\hline & Ort $\pm S s$ & $25.71 \pm 4.98$ & $24.86 \pm 4.12$ & \\
\hline \multirow{2}{*}{ Cinsiyet } & Erkek & $37(56,9)$ & $6(40,0)$ & ${ }^{b} 0.236$ \\
\hline & Kadın & $27(46,3)$ & $9(60,0)$ & \\
\hline \multirow{2}{*}{ Taraf } & Sağ & $29(44,6)$ & $8(53,3)$ & ${ }^{b} 0.542$ \\
\hline & Sol & $36(55,4)$ & $7(46,7)$ & \\
\hline \multirow{2}{*}{$\begin{array}{l}\text { Semptom } \\
\text { süresi }\end{array}$} & $<6$ ay & $52(80,0)$ & $2(20,0)$ & \multirow{2}{*}{$c 0.001^{* *}$} \\
\hline & $>6$ ay & $13(20,0)$ & $12(80,0)$ & \\
\hline \multirow{5}{*}{ Seviye } & L1-L2 & 0 & $2(13,3)$ & ${ }^{d} 0.081$ \\
\hline & L2-L3 & $5(7,7)$ & 0 & \\
\hline & L3-L4 & $13(20,0)$ & $2(13,3)$ & \\
\hline & L4-L5 & $36(55,4)$ & $7(46,7)$ & \\
\hline & L5-S1 & $11(16,9)$ & $4(26,7)$ & \\
\hline
\end{tabular}

a Student $t$ test b Ki kare test c Fisherexcat test dFisher Freeman Halton test ${ }^{* *} \mathrm{p}<0,01$

Olguların işlem öncesi VAS ölçümleri ortalaması 8 iken, işlem sonrası 3. saatte 1'e gerilemiş, 1. ayda kısmen artarak ortalama 2'ye yükselmiș, 3.ayda ise ortalama 2,7'ye yükselmiştir (Şekil 3). VAS değerindeki azalma işlem sonrası 3. saatte ortalama \%84; 1.ayda
\%71,9, 3.ayda ise \%65,5 olarak saptanmıştır. Başarı durumu dikkate alındığında işlem öncesi VAS ölçümleri arasında anlamlı fark saptanmamıştır $(p>0,05)$. İşlem sonrası 3. saat, ișlem sonrası 1 . ay ve ișlem sonrası 3 . ay VAS ölçümleri ise başarılı olgularda anlamlı düzeyde düşük bulunmuştur $(\mathrm{p}<0,05)$ (Tablo2).

Tablo 2: Başarılı ve başarısız olgularda işlem öncesi, işlem sonrası, işlem sonrası 1. ay, işlem sonrası 3. ay VAS değerleri ve VAS değişim miktarları ile başarı durumu arasındaki ilișki.

\begin{tabular}{|c|c|c|c|c|}
\hline & & Başarılı & Başarısız & $p$ \\
\hline \multirow[t]{2}{*}{ Preop VAS } & Min-Mak (Medyan) & 5-10 (8) & $5-9(7)$ & $e 0.076$ \\
\hline & Ort $\pm S s$ & $8.0 \pm 1.0$ & $7.0 \pm 1.0$ & \\
\hline \multirow{2}{*}{ Postop VAS } & Min-Mak (Medyan) & $0-3(1)$ & $0-4(2)$ & e0.040* \\
\hline & Ort $\pm S s$ & $1.0 \pm 0.9$ & $1.8 \pm 1.4$ & \\
\hline \multirow{2}{*}{ 1.ay VAS } & Min-Mak (Medyan) & $0-4(2)$ & $2-5(3)$ & $e 0.001^{* *}$ \\
\hline & Ort $\pm S s$ & $1.9 \pm 0.8$ & $3.2 \pm 1.0$ & \\
\hline \multirow{2}{*}{ 3.ay VAS } & Min-Mak (Medyan) & $0-4(2)$ & $3-6(4)$ & $e 0.001^{* *}$ \\
\hline & Ort $\pm S s$ & $2.2 \pm 0.9$ & $4.6 \pm 0.9$ & \\
\hline \multirow{4}{*}{$\begin{array}{c}\text { İșlem sonrası } 3 . \\
\text { saatte VAS } \\
\text { değișimi (\%) }\end{array}$} & $0-\% 24,9$ & 0 & 0 & \multirow{2}{*}{$c 0.011^{*}$} \\
\hline & $\% 25-\% 49,9$ & 0 & 0 & \\
\hline & $\% 50-\% 74,9$ & $8(57,1)$ & $6(42,9)$ & \\
\hline & $\geq \% 75$ & $57(86,4)$ & $9(13,6)$ & \\
\hline \multirow{4}{*}{$\begin{array}{c}\text { İșlem sonrası } 1 . \\
\text { ayda VAS değişimi }\end{array}$} & $0-\% 24,9$ & 0 & 0 & d0.001** \\
\hline & $\% 25-\% 49,9$ & 0 & $4(100)$ & \\
\hline & $\% 50-\% 74,9$ & $21(67,7)$ & $10(32,3)$ & \\
\hline & $\geq \% 75$ & $44(97,8)$ & $1(2,2)$ & \\
\hline \multirow{4}{*}{$\begin{array}{c}\text { İșlem sonrası } 3 . \\
\text { ayda VAS değişimi }\end{array}$} & $0-\% 24,9$ & 0 & 0 & do.001** \\
\hline & $\% 25-\% 49,9$ & 0 & $15(100)$ & \\
\hline & $\% 50-\% 74,9$ & $26(100)$ & 0 & \\
\hline & $\geq \% 75$ & $39(100)$ & 0 & \\
\hline
\end{tabular}

dFisher Freeman Halton test eMann Whitney U test ${ }^{*} \mathrm{p}<0.05{ }^{* *} \mathrm{p}<0,01$

VAS: Visual analoğu escale 


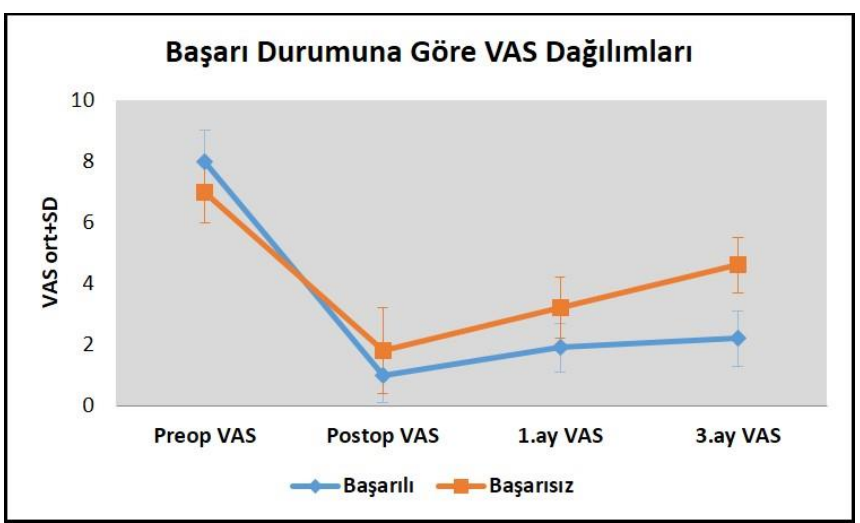

Şekil 3: Çizgi grafikte başarılı ve başarısız olguların VAS (visual analoğue scala) değerlerinin zamana göre değişimi görülmektedir.

\section{TARTIŞMA}

Bel ağrısı toplumda oldukça yaygın görülen, yaşam kalitesini bozan ve günlük hayatı kısitlayan tıbbi ve sosyoekonomik bir problemdir. Bel ağrısına bacak ağrısı da eşlik edebilmekte ve yaşam kalitesini ciddi derecede bozabilen bir faktör olarak bilinmektedir. Bel ağrısına eşlik eden bacak ağrısının en sık nedeni ise lomber disk hernisidir. Bu hastaların yaklaşık \%85'inde konservatif yöntemler yeterli olurken, \%10-15'inde ise cerrahi girişim gerekebilmektedir9,10. Öte yandan cerrahi girişim gerekmeyen ancak bacak ağrıları da konservatif yöntemlerle geçmeyen hastalar da bulunmaktadır. TFEE bu hasta grubu için başvurulan etkili ve güvenli bir ağrı kontrol yöntemidir ${ }^{11-13}$.

Literatürde bahsedilen TFEE endikasyonu esas olarak lomber disk hernisine bağlı radikülopatiler olmasına rağmen TFEE dar kanal, postoperatifepiduralfibroz, epidural lipom gibi lomber patolojilerde de kullanılmıștır ${ }^{14-16 .}$ İnterlaminar, kaudalenjeksiyon tekniklerinden de literatürde sıkça bahsedilmiş ancak özellikle lomber disk hernisine bağlı radikülopatilerde TFEE ön plana çıkmış ve yüksek başarı oranlarıyla dikkat çekmiștir ${ }^{17-20}$. İster preganglionik, ister postganglionik, ister ventral, ister dorsalforaminal enjeksiyon uygulaması olsun, tüm TFEE işlemleri hasta seçimi iyi yapıldığında yüz güldürücü olmaktadır ${ }^{21,22}$. Hatta Manson ve ark. cerrahi için bekleme listesindeki hastalara TFEE işlemi uygulamış ve hastaların \%64'ünde cerrahi gereksinimin ortadan kalktığını belirtmişlerdir ${ }^{23}$. Dahası bu etkinin 5 yll boyunca devam ettiği de bildirilmiştir ${ }^{2}$. Cerrahi gereksinimin ortadan kalktığı hastalarda ciddi bir maliyet azalması sağlandığ 1 bildirilmişs ve TFEE işleminin maliyet-etkinliği vurgulanmıştır ${ }^{1,24}$.

Spinalstenozu olan hastalarda TFEE işleminin başarısı tartışmalıdır. Sadece stenozlu hastaların değerlendirildiği iki çalışmada TFEE işleminin başarı oranı net olarak belirtilmemiştir 25,26 . Delport ve ark. kaudalenjeksiyon ve TFEE yaptıkları spinalstenozlu hastalarda kısmi yanit aldıklarını belirtmişler ancak 'kısmi yanıt' ile ne kastettiklerini açıklamamamışlardır ${ }^{25}$. Karppinen ve ark. yaptıkları çalışmada TFEE işleminin sekestre ve ektrüde disk hernilerinde etkili olmadığını belirtmişlerdir ${ }^{5}$. Benzer şekilde Ghahreman ve ark ise işlemin kök basısının düşük derecede olduğu hastalarda belirgin derecede daha başarılı olduğunu bildirmişlerdir ${ }^{22} . \mathrm{Bu}$ nedenlerden dolayı çalışmamıza stenozu olan hastalar, sekestre ve ekstrüde disk hernisi dâhil edilmemiștir. Biz de klinik uygulamamızda bu tip hastalara TFEE yapılmasını uygun görmemekteyiz.

TFEE işleminin etkinliği değerlendirildiğinde başarı oranlarının \%50-85 arasında değiştiği bildirilmiştir ${ }^{27,28}$. Vad ve ark. yaptıklarırandomize kontrolü çalışmada \%84 başarı oranı bildirmiştir ${ }^{29}$. Başarı oranlarını etkileyen faktörlere bakıldığında; ileri derecede lateral resesstenozu, spondilolistezis, spondiloz, yüksek vücut kitle endeksi ve semptom süresinin uzun olması gibi faktörlerin işlemin başarı oranlarını düşürebileceği rapor edilmiştir ${ }^{26}$. Ghahreman ve ark ve Jeong ve ark. semptom sürelerini 6 aydan kısa ve 6 aydan uzun olarak gruplandırmış ve semptom süresi 6 aydan uzun olan, dolayısıyla nispeten kronik 
olgularda, bașarı oranlarını daha düșük bulmuşlardır ${ }^{7,8}$. Çalışmamızda başarı oranı $\% 81,25$ bulunmuştur. Toplam 80 hastanın 65'inde işlem başarılı kabul edilmiştir. Başarısız olan 15 olgunun 13'ünde ise VAS azalma oranı \%25'in üzerindedir. Ancak başarı kriterimizi karşılamadığı için bu olgular başarısız olarak kabul edilmiştir. Bununla birlikte, başarısız kabul ettiğimiz olgular dahi işlemden bir miktar fayda görmüştür. Başarı oranının yüksekliği muhtemelen hasta seçiminin dikkatli yapılmasıyla ilişkilidir. Literatürle uyumlu olarak semptom süresi kısa olan hastalarda başarı oranları daha yüksek bulundu. Semptom süresi 6 aydan kisa olan nispeten subakut olgularda başarı oranı $\% 80$ iken, semptom süresi 6 ay ve daha uzun olan olguların başarı \%20 olarak saptandı $(\mathrm{p}<0,01)$. Yaş, cinsiyet, işlem yapılan seviye ile işlem başarısı arasındaki ilişkiye bakıldığında literatürde farklı bilgiler yer almaktadır. Çalışmamızda bu değişkenler ile işlem başarısı arasında herhangi bir anlamlı ilişki saptanmamıștır.

İşlemde uzun etkili lokal anestezik ve uzun etkili depo steroidler kullanılmaktadır. Steroid olarak genellikle metilprednizolon, triamsinolon, betametazone ve daha nadir olarak da deksametazon kullanılmaktadır. Bu ilaçlar sadece lokalanestezik veya steroid ve lokal anestezik karışımı șeklinde kullanılmaktadır ${ }^{1,5,9,21,30}$. Isşlemlerimizde steroid olarak metilprednizolon kullanılmıștır. Literatürde $40 \mathrm{mg}$ veya $80 \mathrm{mg}$ olarak iki ayrı kullanım şekli bildirilmiş olup çalışmamızda daha yaygin olarak kullanılan $40 \mathrm{mg}$ tercih edilmiş ve sonuçlar tatmin edici bulunmuştur. Ayrıca literatürdeki uygulamalara bakıldığında sadece 1 enjeksiyon, 1-3 arası enjeksiyon, 1-4 arası enjeksiyon şeklinde hastalara tekrarlayan enjeksiyonlar yapılmıştır. Ancak literatür gözden geçirildiğinde hastaların sadece $\% 4$ 'ünün ikinci enjeksiyona ihtiyaç duyduğu rapor edilmiştir6,12,21,28. Klinik uygulamamızda ikinci enjeksiyon şeklinde bir uygulama yapmamaktayız.

TFEE ilişkili komplikasyon oranları oldukça düşüktür. Her ne kadar, baş ağrısı, işlem sonrası ağrı, vazovagal reaksiyonlar, kızarıklık, geçici motor defisit, baş dönmesi, bulantı gibi durumlar bildirilmiş olsa da MacVicar ve ark. bunların işlem komplikasyonu olarak sayılmaması gerektiğini belirtmişlerdir ${ }^{1}$. Gerçek anlamda TFEE komplikasyonu spinalkordenfarktıdır. $\mathrm{Bu}$ da partiküllü steroidlerin spinal kordu besleyen arterlerden birinin içine enjekte edilmesi sonucunda olmaktadır ve literatürde 8 olgu bildirilmiştir ${ }^{1}$. Olgularımızda herhangi bir komplikasyona rastlanmamıștır.

Çalışmanın bazı limitasyonları vardır. Öncelikle çalışmamız retrospektif bir çalışmadır. Buna ilaveten, 3 aylık takip süresi lomber disk hernisine bağlı radikülopatili hastalarda takip açısından yeterli bir süre olmayabilir. Daha uzun dönem takiplerin yapılması TFEE işleminin uzun dönem etkinliğini aydınlatmak açısından faydalı olabilir. Lomber disk hernilerinde istirahat dahil olmak üzere konservatif tedavi ile disk hernisinde küçülmenin ve spontan iyileşmenin bildirilmiş olması nedeniyle, randomize kontrollü çalışmalarla TEE işleminin spontan iyileşme veya konservatif tedavilere kıyasla etkinlik oranının ortaya konması faydalı olacaktır.

Sonuç olarak, semptomları 6 aydan uzun olan hastalarda başarı oranı düşse de, hasta seçimi iyi yapıldığında TFEE lomber disk hernisine bağlı radikülopatili olgularda orta vadede oldukça etkili bir yöntemdir.

Çıkar Çatışması: Yazar bu yazının hazırlanması ve yayınlanması hususunda çıkar çatışması olmadığını beyan etmiştir.

Finansal Destek: Çalışmamız, herhangi bir fondan maddi destek almamıştır. 
Declaration of Conflicting Interests: The authors hereby declare that they have no conflict of interest.

Financial Disclosure: No financial support was received.

\section{KAYNAKLAR}

1. MacVicar J, King W, Landers $\mathrm{MH}$, et all. The effectiveness of lumbar transforaminal injection of steroids: a comprehensive review with systematic analysis of the published data. Pain Med. 2013; 14: 1428.

2. Riew KD, Park JB, Cho YS, et all. Nerve root blocks in the treatment of lumbar radicular pain. A minimum five-year follow-up. J Bone Joint Surg. 2006; 88: 17225.

3. Bernstein IA, Malik Q, Carville S, et all. Low back pain and sciatica: summary of NICE guidance. BMJ. 2017; 6: 356: 16748.

4. Riew KD, Yin Y, Gilula L, et all. The effect of nerve-root injections on the need for operative treatment of lumbar radicular pain. A pro-spective, randomized, controlled, double-blind study. J Bone Jt Surg Am. 2000; 11: 1589-93.

5. Karppinen J, Malmivaara A, Kurunlahti $M$, et all. Periradicular infiltration for sciatica: a randomized con-trolled trial. Spine. 2001; 26: 1059-67.

6. Lee JW, Kim SH, Choi JY, et all. Transforaminal epidural steroid injection for lumbosacral radiculopathy: Preganglionic versus conventional approach. Korean J Radiol. 2006; 7: 139-44.

7. Jeong HS, Lee J, Kim SH, et all. Effectiveness of transforaminal epidural steroid injection by using a preganglionic approach: A prospective randomized controlled study. Radiology. 2007; 245: 584-90.

8. Vad VB, Bhat AL, Lutz GE, et all. Transforaminal epidural steroid injections in lumbosacral radiculopathy: a pro-spective randomized study. Spine. 2002; 27: 11-6.

9. Ghahreman A, Bogduk N. Predictors of a favorable response to transforaminal injection of steroids in patients with lumbar radicular pain due to disc herniation. Pain Med. 2011; 12: 871-9.

10. Çetin MF, Karaman H, Kavak GÖ, et all. Lumbar radikülopatili hastalarda transforaminal lumbar epidural steroid enjeksiyonlarının etkinliği. Ağrı. 2012; 24: 77-84.
11. Hoy D, Bain C, Williams G, et all. A systematic review of the global prevalence of low back pain. Arthritis Rheum. 2012; 64: 2028-37.

12. Ng L, Chaudhary N, Sell P. The efficacy of corticosteroids in periradicular infiltration for chronic radicular pain: a ran-domized, double-blind, controlled trial. Spine. 2005; 30: 857-62.

13. Tafazal S, Ng L, Chaudhary N, et all. Corticosteroids in periradicular infiltration for radicular pain: a randomised double blind controlled trial. One year results and subgroup analysis. Eur Spine J. 2009; 8: 1220-25.

14. Jeong HS, Lee J, Kim SH, et all. Effectiveness of transforaminal epidural steroid injection by using a preganglionic approach: A prospective randomized controlled study. Radiology. 2007; 245: 584-90.

15. Smith CC, Booker T, Schaufele MK, et all. Interlaminar versus transforaminal epidural steroid injections for the treatment of symptomatic lumbar spinal stenosis. Pain Med. 2010; 11: 1511-5.

16. Park JW, Nam HS, Cho SK, et all. Kambin's triangle approach of lumbar transforaminal epidural injection with spinal stenosis. Ann Rehabil Med. 2011; 35: 83343.

17. Chou R, Hashimoto R, Friedly J, et all. Epidural Corticosteroid Injections for Radiculopathy and Spinal Stenosis: A Systematic Review and Meta-analysis. Ann Intern Med. 2015; 163: 373-81.

18. McClain RF, Kapural L, Mekhail NA. Epidural steroid therapy for back and leg pain: Mechanisms of action and efficacy. Spine J. 2005; 5: 191-201.

19. Roberts ST, Willick SE, Rho ME, et all. Efficacy of lumbosacral transforaminal epidural steroid injections: A systematic review. PM R. 2009; 1: 657-68.

20. Rosenberg SK, Grabinsky A, Kooser C, et all. Effectiveness of transforaminal epidural steroid injections in low back pain: A one-year experience. Pain Physician. 2002; 5: 266-70.

21. Ackerman WE, Ahmad M. The efficacy of lumbar epidural steroid injections in patients with lumbar disc herniations. Anesth Analg. 2007; 104: 1217-22.

22. Kabatas S, Cansever T, Yilmaz C, et all. Transforaminal epidural steroid injection via a preganglionic approach for lumbar spinal stenosis and lumbar discogenic pain with radiculopathy. Neurol India. 2010; 58: 242-58.

23. Ghahreman A, Ferch R, Bogduk N. The efficacy of transforaminal injection of steroids for the treatment of lumbar radicular pain. Pain Med. 2010; 11: 1149-68. 
24. Manson NA, McKeon MD, Abraham EP. Transforaminal epidural steroid injections prevent the need for surgery in patients with sciatica secondary to lumbar disc herniation: a retrospective case series. Can J Surg. 2013; 56: 89-96.

25. Crow W, Willis D. Estimating cost of care for patients with acute low back pain: a retrospective review of patient records. J Am Osteopath Assoc. 2009; 109: 22933.

26. Delport EG, Cucuzzella AR, Marley JK, et all. Treatment of lumbar spinal stenosis with epidural steroid injections: A retrospective outcome study. Arch Phys Med Rehabil. 2004; 85: 479-84.

27. Botwin KP, Gruber RD, Bouchlas CG, et all. Fluoroscopically guided lumbar transformational epidural steroid injections in degenerative lumbar stenosis. An outcome study. Am J Phys Med Rehabil. 2002; 8: 898905.
28. Gharibo CG, Varlotta GP, Rhame EE, et all. Interlaminar versus transforaminal epidural steroids for the treatment of subacute lumbar radicular pain: a randomized, blinded, prospective outcome study. Pain Physician. 2011; 14: 499-511.

29. Cyteval C, Fesquet N, Thomas E, et all. Predictive factors of efficacy of periradicular corticosteroid injections for lumbar radiculopathy. AJNR. Am J Neuroradiol. 2006; 27: 978-82.

30. Vad VB, Bhat AL, Lutz GE, et all. Transforaminal epidural steroid injections in lumbosacral radiculopathy: a prospective randomized study. Spine (Phila Pa 1976). 2002; 27: 11-6.

31. Kircelli A, Yılmaz C. Lomber Disk Hernilerinde Kaudal ve Transforaminal Epidural Steroid Enjeksiyonlarının Birlikte Kullanımının Kısa ve Uzun Dönem Tedavi Sonuçlarına Etkisi. Türk Nöroşir Derg. 2016; 26: 49-54. 